\title{
Silicon(lithiated)-sulfur full cells with porous silicon anode shielded by Nafion against polysulfides to achieve high capacity and energy density
}

Chenfei Shen ${ }^{\mathrm{a}, 1}$, Mingyuan Ge $\mathrm{a}^{\mathrm{a}, 1,2}$, Anyi Zhang ${ }^{\mathrm{a}}$, Xin Fang ${ }^{\mathrm{a}}$, Yihang Liu ${ }^{\mathrm{b}}$, Jiepeng Rong $^{\mathrm{a}}$, Chongwu Zhou, ${ }^{\mathrm{a}, \mathrm{b}, *}$

${ }^{a}$ Mork Family Department of Chemical Engineering and Materials Science, University of Southern California, Los Angeles, California 90089, United States

${ }^{b}$ Ming Hsieh Department of Electrical Engineering, University of Southern California, Los Angeles, California 90089, United States

*Corresponding author.

Email address: chongwuz@usc.edu (C. Zhou).

${ }^{1}$ C. Shen and M. Ge contribute equally to this work.

${ }^{2}$ Present address: National Synchrotron Light Source II, Brookhaven National Laboratory, Upton, New York 11973, United States.

1

(C) 2015. This manuscript version is made available under the Elsevier user license http://www.elsevier.com/open-access/userlicense/1.0/ 


\section{Abstract}

Lithium-ion batteries have attracted great attention as one of the most versatile electrochemical energy storage devices. However, to meet the ever-growing energy needs for wide applications, further improvements on energy density of batteries are expected, which requires the development of innovative high-energy electrode materials. Silicon ( $\mathrm{Si}$ ) and sulfur (S) are two promising candidates and have been studied intensively as anode and cathode materials in lithium-ion batteries. Nevertheless, the excellent performance achieved with Li-Si and Li-S half cells usually does not easily translate to high-performance Si-S full cell. Here, we will discuss the challenges in the $\mathrm{Si}-\mathrm{S}$ full cell integration, and a failure mechanism of $\mathrm{Si}-\mathrm{S}$ full cell is proposed, which is due to the spontaneous reaction between $\mathrm{Si}$ (and lithiated $\mathrm{Si}$ ) and polysulfides. On this basis, we report one prototype of Si-S full cells using lithiated Nafion-coated porous $\mathrm{Si}$ as anode and sulfur as cathode, and our study on the functionality of Nafion in shielding Si from reaction with polysulfides. With optimized mass ratio between sulfur and silicon, the full cell yields specific capacity of $330 \mathrm{mAh} / \mathrm{g}$ and energy density of 590 $\mathrm{Wh} / \mathrm{kg}$ after 100 cycles based on the total mass of sulfur and silicon. The achieved energy density is more than 2 times higher than commercially available lithium-ion batteries. The investigation of issues in $\mathrm{Si}-\mathrm{S}$ full cell research and the proposed full cell prototype will shed light on the development of next-generation lithium-ion batteries.

KEYWORDS: Lithium-ion battery; Full cell; Nafion; Porous Si; Lithium-sulfur battery 


\section{Introduction}

Lithium-ion battery is one type of energy storage devices that can deliver high energy density with high conversion efficiency. Because they are lightweight and environmental friendly, lithium-ion batteries have been widely used for portable electronics. During the past years, emerging market of electric vehicles (EV) and hybrid electric vehicles (HEV) has generated increasing demands for the development of safe batteries with high energy and power densities [1]. Both academia and industry are seeking to advance the capacity and cycle life of electrode materials to replace the currently used graphite anode and lithium metal oxide (or phosphate) based cathode in commercial lithium-ion batteries. Recently, silicon ( $\mathrm{Si}$ ) is emerging as a promising anode material due to its high theoretical capacity $(\sim 3600 \mathrm{mAh} / \mathrm{g})$, which is approximately 10 times of currently used graphite anode [2]. Substantial efforts have been devoted to improve its cyclic performance through engineering silicon into nanostructures, to circumvent the inherent large volume expansion $(\sim 300 \%)$ during the lithiation process, which would otherwise lead to severe electrode pulverization and capacity degradation. A variety of Si nanostructures, such as Si nanowires [3], hollow Si nanostructures [4-7], and porous Si [8-12] have been proposed and have significantly improved the Si anode performance, which leads to a solid step forwards for real battery applications.

Despite the encouraging progress made with $\mathrm{Si}$ anode, the inherent low capacity of traditional cathode materials significantly compromises the utilization of $\mathrm{Si}$ in achieving high capacity and energy density in practical batteries. For instance, a large family of cathode materials, including lithium metal oxide $\left(\mathrm{LiMO}_{2}\right.$, $\mathrm{M}=\mathrm{Co}, \mathrm{Ni}, \mathrm{Mn})$ [13-16] and lithium metal phosphate $\left(\mathrm{LiMPO}_{4}, \mathrm{M}=\mathrm{Fe}, \mathrm{Co}, \mathrm{Ni}, \mathrm{Mn}\right)$ [17], generally have capacities around $150 \mathrm{mAh} / \mathrm{g}$. According to Equation (1), integrating Si with these cathode materials leads to 
highest theoretical specific capacity of $144 \mathrm{mAh} / \mathrm{g}$,

$$
\mathrm{C}_{\text {full cell }}=\frac{\mathrm{C}_{\mathrm{Si}} \times \mathrm{C}_{\mathrm{LiMO}_{2}}}{\mathrm{C}_{\mathrm{Si}}+\mathrm{C}_{\mathrm{LiMO}_{2}}}
$$

in which $C_{S i}$ is the specific capacity of $\mathrm{Si}$ anode (assumed to be $3600 \mathrm{mAh} / \mathrm{g}$ ), and $C_{\mathrm{LiMO}_{2}}$ is the specific capacity of $\mathrm{LiMO}_{2}$ cathode (assumed to be $150 \mathrm{mAh} / \mathrm{g}$ ). It is important to note that Equation (1) only calculates the highest theoretical specific capacity of the full cell when the capacities of anode and cathode are equal. When the capacities of anode and cathode are not equal, the theoretical specific capacity of the full cell is lower than the highest theoretical specific capacity and it is calculated using the lower capacity among anode and cathode divided by the total mass of anode and cathode active materials. Here, the calculated highest theoretical specific capacity of $\mathrm{Si}-\mathrm{LiMO}_{2}$ system is only $36 \%$ higher than that of graphite-LiCoO${ }_{2}$ system, which is $106 \mathrm{mAh} / \mathrm{g}$ if we assume graphite has a capacity of $360 \mathrm{mAh} / \mathrm{g}$. In addition, in order to optimize the loading of electrode materials, excessive amount of cathode is required to balance the loading of $\mathrm{Si}$, which would bring technological difficulties to coat thick and stable layer of cathode material on electrode substrate. It is therefore highly desired to find cathode replacement with higher specific capacity.

Recently, sulfur (S) cathode has attracted great attention, notable for its high theoretical specific capacity $(1675 \mathrm{mAh} / \mathrm{g})$ and reduced cost compared with traditional cathode materials. It therefore holds great promise to investigate the Si-S (lithiated $\mathrm{Si}$ and/or lithiated $\mathrm{S}$ ) full cell, as integration of $\mathrm{Si}$ anode and $\mathrm{S}$ cathode can theoretically deliver specific capacity more than 7 times and energy density more than 3 times higher than both graphite- $\mathrm{LiMO}_{2}$ and the potential $\mathrm{Si}-\mathrm{LiMO}_{2}$ battery systems $[18,19]$. Due to lack of lithium in Si anode and $\mathrm{S}$ cathode, one electrode or both electrodes need to be lithiated before assembled into full cells, and therefore the full cells can be made of $\mathrm{Si}$ (lithiated)-S, Si-S(lithiated), or $\mathrm{Si}$ (lithiated)-S(lithiated). For simplicity, we call all 
three types Si-S full cells and when talking about a specific type of full cell, we will mention which electrode is lithiated in the following discussion. In order to achieve high capacity and energy density of Si-S full cell, the electrochemical performance of both the $\mathrm{Si}$ anode and $\mathrm{S}$ cathode should be optimized. For $\mathrm{Si}$ anode, as mentioned above, the main problem arising from electrode pulverization can be tackled by fabricating nanostructured $\mathrm{Si}$ particle such as porous $\mathrm{Si}$. For $\mathrm{S}$ cathode, the main challenge is to reduce internal redox shuttle between dissoluble polysulfides anions $\left(\mathrm{Li}_{2} \mathrm{~S}_{4-6}\right)$ which leads to pronounced capacity fading and low Coulombic efficiency of electrode [20]. The most popular approach to tackle the problems is to infiltrate sulfur into various host materials to encapsulate the dissolved polysulfides, with aim to alleviate the shuttle effect. Carbon-based materials such as porous carbon, intertwined carbon nanotubes, and graphene are the most widely used sulfur capture matrix [21-24]. Embedding sulfur into other inorganic porous structures is also receiving great attention. Research has demonstrated that the cyclability of Li-S battery can be significantly improved by confining sulfur into $\mathrm{TiO}_{2}[25]$ and $\mathrm{MnO}_{2}[26]$ nanostructures, which not only confines the sulfur species spatially, but also provides weak chemical interactions to trap the dissolved polysulfides with the presence of functional groups at the surface of these oxide materials. However, none of the sulfur-confinement approaches are capable of eliminating the polysulfides dissolution completely. Recently, research has been directed to a different type of approach. By saturating the electrolyte with added lithium polysulfides, dissolution of polysulfides from sulfur cathode during electrochemical cycling can be effectively alleviated [27]. Therefore, polysulfides dissolution in electrolyte to some extent is inevitable in Li-S battery and if it is coupled with $\mathrm{Si}$ anode, spontaneous reaction between $\mathrm{Si}$ (and lithiated $\mathrm{Si}$ ) and polysulfides would take place, which would lead to capacity decay of the full cell. To shed light on Si-S full cell research development, in this work, we will discuss the failure mechanism of Si-S full cell. On this basis, we will provide some effective 
solutions to tackle the problem, and finally present a prototype of Si(lithiated)-S full cell.

\section{Experimental}

\section{Materials preparation}

Synthesis of porous Si particles: Porous Si particles were synthesized according to our previous report [11].

Specifically, metallurgical Si particles were first ground to fine powder using ball-milling operated at grinding speed of $1200 \mathrm{rpm}$ for 5 hours. The Si powder was washed in diluted hydrofluoric acid (HF) and deionized water $\left(\mathrm{DI}-\mathrm{H}_{2} \mathrm{O}\right)$ successively to remove surface oxide layer. The Si power was then soaked in a ferric etchant containing $30 \mathrm{mM} \mathrm{Fe}\left(\mathrm{NO}_{3}\right)_{3}$ and $5 \mathrm{M} \mathrm{HF}$ under continuous stirring. After 2 hours of reaction, precipitates containing porous $\mathrm{Si}$ particles were collected and washed using ethanol and $\mathrm{DI}-\mathrm{H}_{2} \mathrm{O}$. The washed particles were dried for further use.

Nafion coating on porous Si particles: Nafion solution (5 wt.\% in ethanol) was bought from Sigma-Aldrich.

Porous Si particles were soaked in Nafion solution for 12 hours. After that, the particles were centrifuged to remove excessive Nafion, and further washed with DI- $\mathrm{H}_{2} \mathrm{O}$ before drying to get powder. In the paper, this Nafion-coated Si is denoted as Si-N.

Carbon coating on porous Si particles: Chemical vapor deposition (CVD) was used to coat a thin layer of carbon on the surface of porous Si particles. Specifically, porous Si particles were loaded into a tube furnace, and gradually elevated the furnace temperature to $860{ }^{\circ} \mathrm{C}$ in Ar-protected environment. At $860{ }^{\circ} \mathrm{C}$, diluted ethylene $\left(\mathrm{C}_{2} \mathrm{H}_{4}: \mathrm{Ar}=1: 10\right.$ by volume $)$ was fed through, and the tube is kept in ambient pressure. After 15 min reaction, furnace was naturally cooled down to collect the carbon-coated $\mathrm{Si}$. In the paper, this carbon-coated $\mathrm{Si}$ is denoted as $\mathrm{Si}-\mathrm{C}$. 
Nafion coating on Si-C particles: Nafion coating on Si-C particles was followed by the same procedure as used to coat Nafion on Si particles. In the paper, this Nafion-coated Si-C is denoted as Si-C-N.

Graphene oxide coating on Si-C particles: Graphene oxide (GO) was prepared according to modified Hummers method [28]. Si-C particles and GO (10:1 by weight) were mixed in ethanol under continuous stirring for $10 \mathrm{~min}$. Droplets of hydrazine and ammonia were added into the mixed solution, and kept at $90{ }^{\circ} \mathrm{C}$ for 1 hour. GO-coated particles were collected by centrifuge and then washed by $\mathrm{DI}-\mathrm{H}_{2} \mathrm{O}$ twice. The particles were dried to get powder. In the paper, this GO-coated $\mathrm{Si}-\mathrm{C}$ is denoted as $\mathrm{Si}-\mathrm{C}-\mathrm{G}$.

Graphene oxide coating on Si-C-N particles: GO coating on Si-C-N particles was followed by the same procedure as used to coat $\mathrm{GO}$ on Si-C particles. In the paper, this GO-coated Si-C-N is denoted as Si-C-N-G.

Preparation of S cathode material: Elemental sulfur was mixed with carbon black and carbon nanofiber with mass ratio of 10:4:1. The mixture was annealed at $155^{\circ} \mathrm{C}$ for 4 hours to infiltrate $\mathrm{S}$ into the carbon matrix. The mixture was then coated with GO following the same procedure as used to prepare Si-C-G. In the paper, this S-based composite is denoted as S-C-G.

Preparation of Si-based electrode: The active material can be selected from Si, Si-N, Si-C, Si-C-N, Si-C-G, and Si-C-N-G. To prepare electrode, active Si material was first mixed with carbon black and alginic acid sodium salt with mass ratio of 7:2:1.5 in water to form uniform slurry. The slurry was coated on copper foil and then dried at $90{ }^{\circ} \mathrm{C}$ in air for 6 hours.

Preparation of S electrode: To prepare S electrode, S-C-G was mixed with polyvinylidene fluoride with mass ratio of 9:1 in N-methyl-pyrrolidone to form uniform slurry. The slurry was coated on aluminum foil and then dried at $90{ }^{\circ} \mathrm{C}$ in air for 6 hours.

\section{Structural characterization}


The morphology of the materials were investigated by scanning electron microscopy (SEM, JEOL JSM-7001) equipped with an energy dispersive X-ray spectroscopy (EDS) system and transmission electron microscopy (TEM, JEOL JEM-2100F). Fourier transform infrared (FTIR) spectra were recorded on a Bruker VERTEX 80 spectrometer in the wave number range of $4000-500 \mathrm{~cm}^{-1}$. X-ray photoelectron spectroscopy (XPS) measurements were carried out with Kratos Axis Ultra DLD surface analysis instrument using focused monochromatized $\mathrm{Al} \mathrm{K} \alpha$ radiation $(\mathrm{hv}=1486.6 \mathrm{eV})$.

\section{Electrochemical measurements}

For $\mathrm{Li}-\mathrm{Si}$ and $\mathrm{Li}-\mathrm{S}$ half cell measurements, CR2032 coin cells were assembled using lithium foil as counter/reference electrode and Celgard 2400 as separator. The prepared Si-based electrodes or S electrodes were used as working electrodes. Two kinds of electrolytes were used in different experiments: 1. Polysulfides electrolyte: 1 M lithium bis(trifluoromethanesulfonyl)imide (LITFSI) in 1,2-dimethoxyethane (DME)/1,3-dioxolane (DOL), 1:1 by volume, with addition of $1 \mathrm{M} \mathrm{Li}_{2} \mathrm{~S}_{4} ; \mathbf{2}$. LITFSI electrolyte: $1 \mathrm{M}$ LITFSI in DME/DOL, 1:1 by volume, with addition of $5 \% \mathrm{LiNO}_{3}$. The galvanostatic charge-discharge test was carried out in the voltage window of $0.01-2 \mathrm{~V}\left(\mathrm{vs} . \mathrm{Li} / \mathrm{Li}^{+}\right.$) at current density of $400 \mathrm{~mA} / \mathrm{g}$ for Li-Si half cells and in the voltage window of 1.7-2.7 $\mathrm{V}\left(\mathrm{vs} . \mathrm{Li} / \mathrm{Li}^{+}\right)$at current density of $0.1 \mathrm{C}(1 \mathrm{C}=1600 \mathrm{~mA} / \mathrm{g})$ for $\mathrm{Li}-\mathrm{S}$ half cells. The electrochemical impedance spectra (EIS) of Li-Si half cells were collected with an AC voltage of $5 \mathrm{mV}$ amplitude in the frequency range of $1000 \mathrm{kHz}$ to $10 \mathrm{mHz}$.

To make Si(lithiated)-S full cells, Si-based electrodes were first assembled in Li-Si half-cell configuration using LITFSI electrolyte. After being charged and discharged for 5 cycles in the voltage window of 0.01-2 V (vs. $\mathrm{Li} / \mathrm{Li}^{+}$) at a current density of $400 \mathrm{~mA} / \mathrm{g}$, Si-based electrodes were disassembled at lithiated state, and then washed carefully with DME/DOL in Ar-protected environment. After drying in Ar-protected environment, the 
lithiated Si-based electrodes were assembled into full cells with S-C-G cathode using CR2032 coin cells. The separator is Celgard 2400 and electrolyte is LITFSI electrolyte. The galvanostatic charge-discharge test for full cells was carried out in the voltage window of $1.2-2.7 \mathrm{~V}\left(\mathrm{vs} . \mathrm{Li} / \mathrm{Li}^{+}\right.$) at current densities from $0.1 \mathrm{C}$ to $0.8 \mathrm{C}$ ( $1 \mathrm{C}=1600 \mathrm{~mA} / \mathrm{g}$ based on the mass of sulfur). The cyclic voltammetry $(\mathrm{CV})$ of full cells was conducted at scan rate of $0.2 \mathrm{mV} / \mathrm{s}$ in the voltage window of $1.2-2.7 \mathrm{~V}$.

Following conventions in literature, for all the Li-Si half cells in this paper, we define the lithiation process to be charge and delithiation process to be discharge, and the Coulombic efficiency of the Li-Si half cells is defined as the discharge capacity divided by the preceding charge capacity. For all the Li-S half cells, we define the lithiation process to be discharge and delithiation process to be charge, and the Coulombic efficiency of the Li-S half cells is defined as the discharge capacity divided by the following charge capacity. For all the Si(lithiated)-S full cells, we define the lithiation of the S-C-G cathode process to be discharge and the delithiation of the S-C-G cathode process to be charge, and the Coulombic efficiency of the Si(lithiated)-S full cells is defined as the discharge capacity divided by the preceding charge capacity $[29,30]$.

\section{Results and discussion}

In our experiment, we use porous Si particles with multiple protective coatings as anode, and $\mathrm{S}$ infiltrated in a mixture of carbon black, carbon nanofiber, and graphene as cathode (S-C-G). To choose electrolyte for full cells, tests of Li-Si and Li-S half cells using two kinds of electrolytes were conducted and results indicate that both electrolytes which are commonly used for $\mathrm{Si}\left(1 \mathrm{M} \mathrm{LiPF}_{6}\right.$ in dimethyl carbonate (DMC)/fluoroethylene carbonate (FEC), 1:1 by volume) and S (1 M LITFSI in DME/DOL, 1:1 by volume, with addition of 5\% $\mathrm{LiNO}_{3}$ ) deliver similar results for Li-Si system. However, Li-S cells fail to operate in DMC/FEC based 
electrolyte, mainly due to the reaction between polysulfides and carbonate-based electrolytes via a nucleophilic addition or substitution reaction, leading to sudden capacity fading [31]. With the choice of DME/DOL based electrolyte, the full cell using lithiated bare porous $\mathrm{Si}$ as anode and S-C-G as cathode, however, experiences severe capacity degradation after a few cycles despite of their good performance in Li-Si and Li-S half cells (Supporting Information Figure S1). The poor performance of Si-S full cell is attributed to the spontaneous reaction between dissolved polysulfides and $\mathrm{Si}$ (and lithiated $\mathrm{Si}$ ). Based on the chemical potential, the open circuit voltage of $\mathrm{Si}$ is around 2.4-2.8 V (vs. $\left.\mathrm{Li} / \mathrm{Li}^{+}\right)$; the lithiation/delithiation voltages are around $0.2-0.8 \mathrm{~V}$ (vs. $\left.\mathrm{Li} / \mathrm{Li}^{+}\right)$for lithiated $\mathrm{Si}\left(\mathrm{Li}_{x} \mathrm{Si}\right)$, and 1.7-2.4 V (vs. $\left.\mathrm{Li} / \mathrm{Li}^{+}\right)$for polysulfides $\left(\mathrm{Li}_{2} \mathrm{~S}_{\mathrm{y}}\right)$, respectively. When $\mathrm{Si}$ is in contact with polysulfides, chemical reaction can take place between Si and polysulfides. This reaction would consume $\mathrm{Si}$ and Li irreversibly and thus reduce the available capacity of the electrode. During cycling process, $\mathrm{Si}$ will be lithiated and the formed $\mathrm{Li}_{\mathrm{x}} \mathrm{Si}$ will have lower potential than polysulfides, which will lead to reaction between $\mathrm{Li}_{\mathrm{x}} \mathrm{Si}$ and polysulfides as following:

$$
\mathrm{Li}_{\mathrm{x}} \mathrm{Si}+\mathrm{Li}_{2} \mathrm{~S}_{\mathrm{y}} \rightarrow \mathrm{Li}_{\mathrm{x}-\Delta} \mathrm{Si}+\mathrm{Li}_{2+\Delta} \mathrm{S}_{\mathrm{y}}
$$

This lithium ion transfer leads to shuttle effect in the Si(lithiated)-S full cell, which will result in capacity degradation during cycling process.

To circumvent the shuttle effect resulted from direct attack by polysulfides, a protective coating layer on the surface of $\mathrm{Si}$ is highly desired. During the past years, fluoropolymer-copolymer based on sulfonated tetrafluoroethylene, known as Nafion, has received considerable attention as a proton conductor for proton exchange membrane fuel cells [32]. The sulfonate functional group $\left(-\mathrm{SO}_{3}{ }^{-}\right)$can effectively prevent the approaching of negative-charged anions due to electrostatic repulsion force. Inspired by the impermeability of 
Nafion for anions, we have come up with the idea of conformally coating a thin layer of Nafion on $\mathrm{Si}$, and then evaluating its functionality to shield $\mathrm{Si}$ (and lithiated $\mathrm{Si}$ ) from spontaneous reaction with polysulfides in $\mathrm{Si}-\mathrm{S}$ full cell.

To elucidate the function of Nafion, one piece of bare Si wafer and another piece of Si wafer with Nafion coating were immersed in the same polysulfides electrolyte (1 M LITFSI in DME/DOL, 1:1 by volume, with addition of $\left.1 \mathrm{M} \mathrm{Li}_{2} \mathrm{~S}_{4}\right)$. Figure 1 schematically shows the concept of the experiments. As shown in Figure 1a, when a bare $\mathrm{Si}$ wafer is immersed into the electrolyte, spontaneous reaction between $\mathrm{Si}$ and polysulfides would occur. To identify the product of the reaction, EDS and XPS analyses were performed (Supporting Information Figure S2), suggesting the reaction product to be Li-Si-S compound. After reaction for 12 hours, the wafer was then washed with $\mathrm{DI}-\mathrm{H}_{2} \mathrm{O}$, during which process the formed $\mathrm{Li}-\mathrm{Si}-\mathrm{S}$ compound reacted with water. As a result, the original clean surface of Si wafer would become rough. Figure 1b shows a SEM image of the bare Si wafer after the reaction and then being washed by DI- $\mathrm{H}_{2} \mathrm{O}$. The SEM image clearly shows a rough surface of the wafer, indicating the etching of wafer due to the spontaneous reaction. To shield Si wafer from reaction with polysulfides, the other wafer was coated with a thin layer of Nafion by spin coating (Figure 1c), and then treated in the same way as the bare wafer. From the SEM image shown in Figure 1d, the clean and smooth surface of wafer confirms that the reaction between $\mathrm{Si}$ and polysulfides is effectively circumvented due to the protection by Nafion.

To assemble full cells, porous Si particles are used as the anode material, because they have demonstrated good cyclic performance in Li-Si half cells and the preparation method is cost-effective and scalable as 
reported in our previous work [11]. Specifically, metallurgical Si was milled to submicron particles, and then got etched in a ferric etchant, leaving a highly porous structure. As-synthesized porous Si particles were then dispersed in Nafion solution ( $5 \mathrm{wt} . \%$ in ethanol) overnight to coat a thin layer of Nafion on particle surface (the product is named $\mathrm{Si}-\mathrm{N}$ ). Figure 2a shows the TEM image of a typical pristine porous particle. Numerous pores are uniformly distributed throughout the whole particle with pore size of around 10-15 nm, which can be clearly resolved in the high resolution TEM (HRTEM) image as shown in Figure 2b. After Nafion coating, there is no significant change in the particle morphology (Figure 2c); however, the porous feature is not as clear as it shows in pristine Si particles, mainly due to the filling of Nafion into the porous structure. From the HRTEM image of Nafion-coated Si in Figure 2d, it is easy to identify the amorphous layer on the periphery of particle with a thickness of approximately $2-4 \mathrm{~nm}$ as indicated by the dotted line. To further confirm the existence of Nafion and rule out the possibility of native silicon oxide in the amorphous layer, we have collected energy filtered electron signals for specific $\mathrm{Si}$ and $\mathrm{S}$ elements to map out the $\mathrm{Si}$ and Nafion distribution (S element is from Nafion). TEM image in Figure 2e shows the region of interest, and Figure 2f-h show the elemental distribution of $\mathrm{Si}, \mathrm{S}$, and their superposition. From Figure $2 \mathrm{~h}$, signals from $\mathrm{Si}$ and $\mathrm{S}$ are well overlapped, which confirms the uniform coating of Nafion on the surface of Si. FTIR spectra of Si, Si-N, and Nafion were also obtained to confirm the coating of Nafion on Si (Supporting Information Figure S3). The characteristic peaks of Nafion at 1226, 1148, 1060, and $982 \mathrm{~cm}^{-1}$ correspond to asymmetric stretching of $\mathrm{CF}_{2}$ group, symmetric stretching of $\mathrm{CF}_{2}$ group, $\mathrm{SO}$ group, and $\mathrm{CFRCF}_{3}$ group, respectively [33]. These peaks are also observed in $\mathrm{Si}-\mathrm{N}$ with much lower intensity, indicating that very thin layer of Nafion is coated onto $\mathrm{Si}$ particles, which is consistent with the TEM observation in Figure 2d. 
Before assembling Si into full cells, galvanostatic charge-discharge test of porous Si particles with and without Nafion coating were first conducted in Li-Si half-cell configuration in the voltage window of 0.01-2 V (vs. $\mathrm{Li} / \mathrm{Li}^{+}$), and the results are shown in Figure 3a. Here, polysulfides electrolyte (1 M LITFSI in DME/DOL, 1:1 by volume, with addition of $\left.1 \mathrm{M} \mathrm{Li}_{2} \mathrm{~S}_{4}\right)$ is used as electrolyte to test the functionality of Nafion and the current density is $400 \mathrm{~mA} / \mathrm{g}$. Despite a gradual capacity loss, capacity of Nafion-coated porous $\mathrm{Si}$ (Si-N) remains $670 \mathrm{mAh} / \mathrm{g}$ after 100 cycles. On the contrary, the cell using bare Si particles drops to almost zero capacity within 20 cycles. The fast capacity degradation results from side reaction between $\mathrm{Li}_{\mathrm{x}} \mathrm{Si}$ anode and polysulfides, as denoted in Equation (2).

In Figure $3 b$, full cells were fabricated to further demonstrate the functionality of Nafion. The anode materials are porous $\mathrm{Si}$ with carbon coating $(\mathrm{Si}-\mathrm{C})$, and porous $\mathrm{Si}$ with carbon coating and Nafion coating (Si-C-N), respectively. Here the porous Si particles were first coated with carbon, because conventionally, a thin layer of carbon coating is found to be beneficial to improve the Coulombic efficiency of Li-Si half cells, as the carbon layer is helpful to form stable SEI layer and reduce side reaction of Si with electrolyte. The cathode material is S-C-G. The morphology and electrochemical performance of S-C-G are demonstrated in Figure S4 in Supporting Information. Before assembling into full cells, the prepared Si anodes were first charged and discharged for 5 cycles in Li-Si half cells. After cycling, Si electrodes were disassembled at lithiated state, and then washed carefully with DME/DOL. After drying in Ar-protected environment, the Si electrodes were assembled into full cells with S-C-G cathode using LITFSI electrolyte (1 M LITFSI in DME/DOL, 1:1 by volume, with addition of $5 \% \mathrm{LiNO}_{3}$ ). We note that there are some recent reports on stable $\mathrm{Li}_{x} \mathrm{Si}$ in air, which may facilitate the pre-lithiation process for Si-S full cells [34,35]. The galvanostatic charge-discharge test of 
full cells was conducted in the voltage window of $1.2-2.7 \mathrm{~V}\left(\mathrm{vs} . \mathrm{Li} / \mathrm{Li}^{+}\right)$at a current density of $0.1 \mathrm{C}(1$ $\mathrm{C}=1600 \mathrm{~mA} / \mathrm{g}$ based on the mass of sulfur) and the capacity is calculated based on the mass of sulfur. As shown in Figure 3b, it is clear to notice the improved cyclability when Nafion is coated. After 200 cycles, the full cell with Si-C anode shows a fast capacity drop to $80 \mathrm{mAh} / \mathrm{g}$. On the contrary, the capacity of the full cell with Si-C-N anode is well above that of the full cell with Si-C anode during 200 cycles. After 200 cycles, the full cell with Si-C-N anode still retains capacity of $170 \mathrm{mAh} / \mathrm{g}$. In addition, Coulombic efficiency of Si-C-N full cell is much higher than that of Si-C full cell, indicating that Nafion layer can effectively reduce the polysulfides shuttle effect. We note that the Coulombic efficiency is higher than $100 \%$ for the initial several cycles. Our observation is consistent with previous reports [36,37], and the mechanism is that in initial several cycles of Li-S half cells, the utilization of sulfur in cathode increases gradually during discharge process as the sulfur in the cathode gradually becomes exposed to the electrolyte. Upon charge process, however, only long chain polysulfides are formed, leading to lower charge capacity than discharge capacity and therefore the Coulombic efficiency is higher than $100 \%$. This explanation can also be applied for our Si(lithiated)-S full cells, which explains why the Coulombic efficiency of the initial several cycles in Figure $3 b$ is higher than $100 \%$.

To further improve the full-cell performance, Nafion-coated Si particles were wrapped with graphene (Si-C-N-G) because graphene can improve the overall electric conductivity of the electrode and it is also helpful to hold particles together without losing their electric contacts during cycling. The morphology and electrochemical performance of Si-C-N-G are demonstrated in Figure S5 in Supporting Information. Figure 4 shows the electrochemical performance of the Si-S full cell with LITFSI electrolyte using lithiated Si-C-N-G 
as anode and S-C-G as cathode. The Si-S full cell is cycled in the voltage window of 1.2-2.7 V and the specific capacity is calculated based on the mass of sulfur. Figure 4a shows the cyclic performance at a current density of $0.1 \mathrm{C}$. After 100 cycles, the charge capacity is $610 \mathrm{mAh} / \mathrm{g}$, which is $80 \%$ of its initial capacity, and the Coulombic efficiency is maintained at $92 \%$. The $\mathrm{Si}-\mathrm{S}$ full cell is determined to have two discharge voltage plateaus of $2.0 \mathrm{~V}$ and $1.7 \mathrm{~V}$, as shown in Figure $4 \mathrm{~b}$, which corresponds well with the difference of voltage plateaus in $\mathrm{Li}-\mathrm{S}$ (two voltage plateaus at 2.4 and $2.1 \mathrm{~V}\left(\mathrm{vs} . \mathrm{Li} / \mathrm{Li}^{+}\right)$) and $\mathrm{Li}-\mathrm{Si}$ (voltage plateau at approximately $0.4 \mathrm{~V}\left(\right.$ vs. $\left.\mathrm{Li} / \mathrm{Li}^{+}\right)$) half cells, as illustrated in Supporting Information Figure S4d and Figure S5d. We note that the sloped curves of both charge and discharge branches in Figure $4 \mathrm{~b}$ are mainly due to the gradually changed voltage profile of amorphous Si anode (Supporting Information Figure S5d). Figure 4c shows the CV curves of Si-S full cell under different cycles. From the CV curves, it is interesting to note that the anodic peak gradually shifts to low potential when the cell is under repeated cycling. This shift is mainly due to the decrease of electron and ion diffusion resistance of the cell, as indicated by the impedance tests shown in Supporting Information Figure S6. However, in the cathodic branch, we note that the high voltage peak (1.9-2.0 V) also shifts to low potential along with cycling, suggesting the gradual dissolution of elemental sulfur and transformation from high-order polysulfides (e.g. $\mathrm{Li}_{2} \mathrm{~S}_{8}$ ) to relative lower-order polysulfides (e.g. $\mathrm{Li}_{2} \mathrm{~S}_{6}$ ). In contrast, the low voltage peak $(\sim 1.6 \mathrm{~V})$, which is mostly related to reactions among solid sulfide species (e.g. $\mathrm{Li}_{2} \mathrm{~S}$ and $\mathrm{Li}_{2} \mathrm{~S}_{2}$ ), does not change peak position significantly [21,38]. Figure $4 \mathrm{~d}$ shows the cyclic performance of Si-S full cell tested at current rates of $0.1 \mathrm{C}, 0.2 \mathrm{C}, 0.4 \mathrm{C}$, and $0.8 \mathrm{C}$ for 10 cycles each. The capacities are stabilized at about $750 \mathrm{mAh} / \mathrm{g}, 600 \mathrm{mAh} / \mathrm{g}, 500 \mathrm{mAh} / \mathrm{g}$, and $400 \mathrm{mAh} / \mathrm{g}$, respectively. After switching back to $0.2 \mathrm{C}$, the capacity retains $550 \mathrm{mAh} / \mathrm{g}$, which implies the good stability of Si-S full cell under different operation rates. To characterize the morphology of the Si-C-N-G electrode before and after cycling, SEM 
images and EDS mappings of the electrodes before and after cycling are shown in Supporting Information Figure S7 and Figure S8.

To make battery practical, the amount of cathode and anode loading is critical to achieve high overall specific capacity and energy density. Unbalanced loading would significantly lower the specific capacity and increase the production cost because of the waste of excessive amount of cathode or anode materials. Currently, Li-S battery has attracted great attention due to its high capacity. However, it is important to note that excessive amount of $\mathrm{Li}$ is used in the cell, which not only lowers the Li-S cell capacity if we take into account the weight of Li, but also brings special concern on battery safety. Recently, great progress has been made to achieve safe Li anode by coating a protective layer on $\mathrm{Li}$, such as single layer boron nitride [39] and hollow carbon layer [40]. Other strategies include electrodeposition of Li on porous substrate [41], or use specialized electrolyte additive such as $\mathrm{LiF}$ and $\mathrm{LiBr}$ to suppress the lithium dendrite formation [42]. However, previously reported approaches are still far from practical usage, and need further investigation on precise control of lithium used for Li-S battery, as well as side effects from the additives. For example, $\mathrm{F}^{-}$is found detrimental to most of cathode materials, and the effect from $\mathrm{Br}_{2}$ precipitation during cell operation is not clear at this moment [42].

In this context, we believe using lithiated $\mathrm{Si}$ as anode has great potential and deserves more research effort, because lithiated $\mathrm{Si}$ is safe (there is no dendrite formation) and it is easy to control the amount of loading. Here, we have investigated the battery performance of Si-S full cells with different mass ratios between S-C-G and Si-C-N-G. Figure 5a shows the cyclic performance of Si-S full cells with S:Si mass ratio of 0.33, 1.43, 2.22, 
and 4.24. The galvanostatic charge-discharge test was conducted in the voltage window of 1.2-2.7 $\mathrm{V}$ at a current density of $0.1 \mathrm{C}$ and the specific discharge capacity is calculated based on the mass of sulfur. We find that in case of large $\mathrm{S}$ loading $(\mathrm{S}: \mathrm{Si}=4.24)$, the capacity drops from $180 \mathrm{mAh} / \mathrm{g}$ to almost 0 after 100 cycles, the low capacity is mainly due to the insufficient lithium provided by the small amount of lithiated Si anode. By decreasing sulfur loading to $\mathrm{S}: \mathrm{Si}=2.22$, the initial capacity increases to $690 \mathrm{mAh} / \mathrm{g}$, and the cell is reasonably stable as the capacity is retained at $280 \mathrm{mAh} / \mathrm{g}$ after 100 cycles. Further decreasing the $\mathrm{S}$ loading to $\mathrm{S}: \mathrm{Si}=1.43$ raises the initial capacity up to $1000 \mathrm{mAh} / \mathrm{g}$, and the capacity stays above $560 \mathrm{mAh} / \mathrm{g}$ for $100 \mathrm{cycles}$, which follows a trend similar to S-C-G cathode in Li-S half-cell configuration (Supporting Information Figure $\mathrm{S} 4 \mathrm{c})$. When $\mathrm{S}$ loading further decreases to $\mathrm{S}: \mathrm{Si}=0.33$, however, the full cell capacity decreases. We believe this is due to the small amount of sulfur used in the cell, and dissolution of sulfur into electrolyte leads to loss of active sulfur in the cathode. We note that it is possible to decrease the amount of electrolyte used in battery to minimize the inevitable sulfur dissolution; however, certain amount of electrolyte is required to wet both cathode and anode. Figure 5b summarizes the specific discharge capacities of the full cells after 100 cycles calculated based on mass of $\mathrm{S}$ and mass of $\mathrm{S}+\mathrm{Si}$, respectively. The highest capacity achieved in our test is 330 $\mathrm{mAh} / \mathrm{g}$ when the total mass of $\mathrm{S}$ and $\mathrm{Si}$ is considered. For comparison, the theoretical capacity of graphite- $\mathrm{LiCoO}_{2}$ full cell at different mass ratios is demonstrated in Figure 5b as black curve. If we assume $\mathrm{LiCoO}_{2}$ has a capacity of $150 \mathrm{mAh} / \mathrm{g}$ and graphite has a capacity of $360 \mathrm{mAh} / \mathrm{g}$, the highest theoretical capacity of graphite- $\mathrm{LiCoO}_{2}$ full cell is $106 \mathrm{mAh} / \mathrm{g}$ when the mass ratio of $\mathrm{LiCoO}_{2}$ to graphite is 2.4. The 330 $\mathrm{mAh} / \mathrm{g}$ achieved in our test is more than three times higher than the highest theoretical capacity of graphite- $\mathrm{LiCoO}_{2}$ full cell. If we use an average operation voltage of $1.8 \mathrm{~V}$ for $\mathrm{Si}$ (lithiated)-S full cell (Figure 4b), the estimated energy density is $590 \mathrm{Wh} / \mathrm{kg}$. For graphite- $\mathrm{LiCoO}_{2}$ full cell, if we use an average operation 
voltage of $3.9 \mathrm{~V}$, the highest theoretical energy density is $410 \mathrm{Wh} / \mathrm{kg}$. However, the actual energy density achieved in industry is $\sim 250 \mathrm{Wh} / \mathrm{kg}$ according to literature $[29,43]$. The energy density of $590 \mathrm{Wh} / \mathrm{kg}$ achieved by our work is therefore more than 2 times higher than that of commercially available lithium-ion batteries and $43 \%$ higher than that of the highest theoretical energy density of graphite- $\mathrm{LiCoO}_{2}$ full cell.

\section{Conclusion}

In summary, we have addressed the critical issue in the implantation of Si-S full battery. Spontaneous reaction between $\mathrm{Si}$ (and lithiated $\mathrm{Si}$ ) and dissolved polysulfides causes significant shuttle effect, which leads to severe capacity degradation. Nafion coating provides an effective way to shield $\mathrm{Si}$ from direct contact with polysulfides, and thus diminish the undesirable side reaction between $\mathrm{Si}$ (and lithiated $\mathrm{Si}$ ) and polysulfides. We have demonstrated the Si-S full cell using lithiated Nafion-coated porous Si as anode and S as cathode. With optimized mass loading ratio of $\mathrm{S}$ to $\mathrm{Si}$, high capacity of the full cell has been achieved. The capacity is 560 $\mathrm{mAh} / \mathrm{g}$ based on the mass of sulfur, and $330 \mathrm{mAh} / \mathrm{g}$ based on the total mass of $\mathrm{S}$ and $\mathrm{Si}$ after 100 cycles. The estimated energy density of the $\mathrm{Si}-\mathrm{S}$ full cell is $590 \mathrm{Wh} / \mathrm{kg}$, which is more than 2 times higher than that of commercially available lithium-ion batteries. We believe the reported various issues involved in Si-S full cell and the approach we have taken to address the issues can open up the door to further optimization of the cell, and lead to a significant step towards the design of new generation of batteries by taking advantages of high-capacity anode and cathode. 


\section{Acknowledgement}

SEM and TEM images used in this article were generated at the Center for Electron Microscopy and Microanalysis, University of Southern California. Mingyuan Ge finished the research reported in this paper at University of Southern California, and contributed to discussions after he joined Brookhaven National

Laboratory. Mingyuan Ge acknowledged the support of Brookhaven National Laboratory, which was supported by the U.S. Department of Energy, Office of Science, Office of Basic Energy Sciences, under Contract No. DE-SC0012704. 


\section{References}

[1] P. G. Bruce, B. Scrosati, J. M. Tarascon, Angew. Chem. Int. Ed. 47 (2008) 2930-2946.

[2] M. N. Obrovac, L. Christensen, Electrochem. Solid State Lett. 7 (2004) A93-A96.

[3] C. K. Chan, H. Peng, G. Liu, K. McIlwrath, X. F. Zhang, R. A. Huggins, Y. Cui, Nat. Nanotechnol. 3 (2008) 31-35.

[4] M. H. Park, M. G. Kim, J. Joo, K. Kim, J. Kim, S. Ahn, Y. Cui, J. Cho, Nano Lett. 9 (2009) 3844-3847.

[5] T. Song, J. Xia, J. H. Lee, D. H. Lee, M. S. Kwon, J. M. Choi, J. Wu, S. K. Doo, H. Chang, W. Il Park, D. S. Zang, H. Kim, Y. G. Huang, K. C. Hwang, J. A. Rogers, U. Paik, Nano Lett. 10 (2010) 1710-1716.

[6] A. Magasinski, P. Dixon, B. Hertzberg, A. Kvit, J. Ayala, G. Yushin, Nat. Mater. 9 (2010) 353-358.

[7] Y. Yao, M. T. McDowell, I. Ryu, H. Wu, N. Liu, L. Hu, W. D. Nix, Y. Cui, Nano Lett. 11 (2011) 2949-2954.

[8] M. Ge, J. Rong, X. Fang, C. Zhou, Nano Lett. 12 (2012) 2318-2323.

[9] H. Kim, B. Han, J. Choo, J. Cho, Angew. Chem. Int. Ed. 47 (2008) 10151-10154.

[10] M. Ge, X. Fang, J. Rong, C. Zhou, Nanotechnology 24 (2013) 422001-422010.

[11] M. Ge, Y. Lu, P. Ercius, J. Rong, X. Fang, M. Mecklenburg, C. Zhou, Nano Lett. 14 (2014) 261-268.

[12] H. Tian, X. Tan, F. Xin, C. Wang, W. Han, Nano Energy 11 (2015) 490-499.

[13] R. J. Gummow, A. Dekock, M. M. Thackeray, Solid State Ionics 69 (1994) 59-67.

[14] A. R. Armstrong, P. G. Bruce, Nature 381 (1996) 499-500.

[15] J. M. Tarascon, M. Armand, Nature 414 (2001) 359-367.

[16] M. S. Whittingham, Chem. Rev. 104 (2004) 4271-4301.

[17] A. K. Padhi, K. S. Nanjundaswamy, J. B. Goodenough, J. Electrochem. Soc. 144 (1997) 1188-1194.

[18] Y. Yang, M. T. McDowell, A. Jackson, J. J. Cha, S. S. Hong, Y. Cui, Nano Lett. 10 (2010) 1486-1491.

[19] N. Liu, L. Hu, M. T. McDowell, A. Jackson, Y. Cui, ACS Nano 5 (2011) 6487-6493.

[20] Y. V. Mikhaylik, J. R. Akridge, J. Electrochem. Soc. 151 (2004) A1969-A1976.

[21] X. Ji, K. T. Lee, L. F. Nazar, Nat. Mater. 8 (2009) 500-506.

[22] G. Zheng, Y. Yang, J. J. Cha, S. S. Hong, Y. Cui, Nano Lett. 11 (2011) 4462-4467.

[23] X. B. Cheng, J. Q. Huang, Q. Zhang, H. J. Peng, M. Q. Zhao, F. Wei, Nano Energy. 4 (2014) 65-72.

[24] H. Wang, Y. Yang, Y. Liang, J. T. Robinson, Y. Li, A. Jackson, Y. Cui, H. Dai, Nano Lett. 11 (2011) 2644-2647.

[25] Z. W. Seh, W. Li, J. J. Cha, G. Zheng, Y. Yang, M. T. McDowell, P. C. Hsu, Y. Cui, Nat. Commun. 4 (2013) 1331-1336.

[26] X. Liang, C. Hart, Q. Pang, A. Garsuch, T. Weiss, L. F. Nazar, Nat. Commun. 6 (2015) 5682-5689.

[27] Y. Qiu, W. Li, W. Zhao, G. Li, Y. Hou, M. Liu, L. Zhou, F. Ye, H. Li, Z. Wei, S. Yang, W. Duan, Y. Ye, J. Guo, Y. Zhang, Nano Lett. 14 (2014) 4821-4827.

[28] D. C. Marcano, D. V. Kosynkin, J. M. Berlin, A. Sinitskii, Z. Sun, A. Slesarev, L. B. Alemany, W. Lu, J. M. Tour, ACS Nano 4 (2010) 4806-4814.

[29] S. K. Lee, S. M. Oh, E. Park, B. Scrosati, J. Hassoun, M. S. Park, Y. J. Kim, H. Kim, I. Belharouak, Y. K. Sun, Nano Lett. 15 (2015) 2863-2868.

[30] M. Agostini, B. Scrosati, J. Hassoun, Adv. Energy Mater. 5 (2015) 1500481.

[31] T. Yim, M. S. Park, J. S. Yu, K. J. Kim, K. Y. Im, J. H. Kim, G. Jeong, Y. N. Jo, S. G. Woo, K. S. Kang, I. Lee, Y. J. Kim, Electrochim. Acta 107 (2013) 454-460. 
[32] K. D. Kreuer, J. Membr. Sci. 185 (2001) 29-39.

[33] Z. Liang, W. Chen, J. Liu, S. Wang, Z. Zhou, W. Li, G. Sun, Q. Xin, J. Membr. Sci. 233 (2004) 39-44.

[34] J. Zhao, Z. Lu, N. Liu, H. W. Lee, M. T. McDowell, Y. Cui, Nat. Commun. 5 (2014) 5088.

[35] J. Zhao, Z. Lu, H. Wang, W. Liu, H. W. Lee, K. Yan, D. Zhuo, D. Lin, N. Liu, Y. Cui, J. Am. Chem. Soc. 137 (2015) 8372-8375.

[36] R. Elazari, G. Salitra, A. Garsuch, A. Panchenko, D. Aurbach, Adv. Mater. 23 (2011) 5641-5644.

[37] Y. S. Su, A. Manthiram, Nat. Commun. 3 (2012) 1166.

[38] P. G. Bruce, S. A. Freunberger, L. J. Hardwick, J. M. Tarascon, Nat. Mater. 11 (2012) 19-29.

[39] K. Yan, H. W. Lee, T. Gao, G. Zheng, H. Yao, H. Wang, Z. Lu, Y. Zhou, Z. Liang, Z. Liu, S. Chu, Y. Cui, Nano Lett. 14 (2014) 6016-6022.

[40] G. Zheng, S. W. Lee, Z. Liang, H. W. Lee, K. Yan, H. Yao, H. Wang, W. Li, S. Chu, Y. Cui, Nat. Nanotechnol. 9 (2014) 618-623.

[41] Z. Liang, G. Zheng, C. Liu, N. Liu, W. Li, K. Yan, H. Yao, P.-C. Hsu, S. Chu, Y. Cui, Nano Lett. 15 (2015) 2910-2916.

[42] Y. Lu, Z. Tu, L. A. Archer, Nat. Mater. 13 (2014) 961-969.

[43] R. Van Noorden, Nature 507 (2014) 26-28. 


\section{Figure captions}

Figure 1 Functionality of Nafion in shielding Si from reaction with polysulfides. (a) Schematic diagram showing the reaction of a bare Si wafer with polysulfides electrolyte (1 M LITFSI in DME/DOL, 1:1 by volume, with addition of $1 \mathrm{M} \mathrm{Li}_{2} \mathrm{~S}_{4}$ ). After the reaction, a thin layer of Li-Si-S compound is formed on the surface of the wafer. (b) SEM image of Si wafer after being immersed in polysulfides electrolyte for 12 hours and washed by DI- $\mathrm{H}_{2} \mathrm{O}$. The rough surface indicates the reaction between $\mathrm{Si}$ and polysulfides. (c) Schematic diagram showing a thin layer of Nafion coating on Si wafer can shield Si from reaction with polysulfides. (d) SEM image of Nafion-coated Si wafer after being immersed in polysulfides electrolyte for 12 hours and washed by DI- $\mathrm{H}_{2} \mathrm{O}$, which shows clean and smooth surface.

Figure 2 Characterization of porous $\mathrm{Si}$ and Nafion-coated porous $\mathrm{Si}(\mathrm{Si}-\mathrm{N}) .(\mathrm{a}, \mathrm{b}) \mathrm{TEM}$ images of a typical porous Si particle at different magnifications. The pores are uniformly distributed throughout the particle, with pore size of 10-15 nm. (c,d) TEM images of Si-N at different magnifications. The porous structure is not as clear as it shows in (a), mainly due to the filling of Nafion into the pores. A thin layer of Nafion can be found in (d) as indicated by the dotted line. (e) Another TEM image of Si-N particle. (f-h) Energy filtered TEM images of (e) to map out the distribution of Si (f), Nafion (g), and their superposition (h).

Figure 3 Electrochemical performance of Li-Si half cells and Si-S full cells to demonstrate the functionality of Nafion. (a) Comparison of Li-Si half cells using bare porous Si particles and Nafion-coated porous Si particles $(\mathrm{Si}-\mathrm{N})$ as working electrode, respectively. The galvanostatic charge-discharge test was conducted in the voltage window of $0.01-2 \mathrm{~V}$ at a current density of $400 \mathrm{~mA} / \mathrm{g}$ and the electrolyte is polysulfides electrolyte $(1 \mathrm{M}$ 
LITFSI in DME/DOL, 1:1 by volume, with addition of $1 \mathrm{M} \mathrm{Li}_{2} \mathrm{~S}_{4}$ ). (b) Comparison of Si-S full cells using lithiated carbon-coated porous $\mathrm{Si}(\mathrm{Si}-\mathrm{C})$ and lithiated carbon-coated porous $\mathrm{Si}$ with Nafion coating (Si-C-N) as anode, respectively. The Si-based anodes were first cycled in $\mathrm{Li}$-Si half cells and then disassembled at lithiated state before coupling with S-C-G cathodes to assemble full cells. The galvanostatic charge-discharge test of full cells was conducted in the voltage window of $1.2-2.7 \mathrm{~V}$ at a current density of $0.1 \mathrm{C}(1 \mathrm{C}=1600 \mathrm{~mA} / \mathrm{g}$ based on the mass of sulfur) and the electrolyte is LITFSI electrolyte (1 M LITFSI in DME/DOL, 1:1 by volume, with addition of $5 \% \mathrm{LiNO}_{3}$ ). The specific capacity is calculated based on the mass of sulfur. Charge capacity: solid circles and solid squares; discharge capacity: hollow circles and hollow squares.

Figure 4 Electrochemical performance of Si-S full cell with LITFSI electrolyte using lithiated Si-C-N-G as anode and $\mathrm{S}-\mathrm{C}-\mathrm{G}$ as cathode. The $\mathrm{Si}-\mathrm{S}$ full cell is cycled in the voltage window of 1.2-2.7 V and the specific capacity is calculated based on the mass of sulfur. (a) Cyclic performance of Si-S full cell at a current density of 0.1 C. (b) Charge-discharge curves of Si-S full cell at different cycles. (c) Cyclic voltammetry curves of Si-S full cell at different cycles. The test is conducted at the scan rate of $0.2 \mathrm{mV} / \mathrm{s}$ in the voltage window of 1.2-2.7 V. (d) Cyclic performance of Si-S full cell at different current rates.

Figure 5 Evaluation of cyclic performance of Si-S full cell with different S:Si mass loading ratios. (a) Cyclic performance of Si-S full cell at S:Si mass loading ratio of $0.33,1.43,2.22$, and 4.24. The galvanostatic charge-discharge test was conducted in the voltage window of $1.2-2.7 \mathrm{~V}$ at a current density of $0.1 \mathrm{C}$ and the specific discharge capacity is calculated based on the mass of sulfur. (b) Calculated specific discharge capacity of Si-S full cell after 100 cycles at different S:Si mass ratios, based on the mass of S only (red curve) and mass 
of $\mathrm{S}+\mathrm{Si}$ (blue curve). For comparison, the theoretical capacity of graphite- $\mathrm{LiCoO}_{2}$ full cell at different mass ratios is demonstrated as black curve. 
Figure 1

(a)

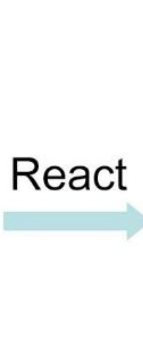

(c) $\mathrm{Li}_{2} \mathrm{~S}_{4}$
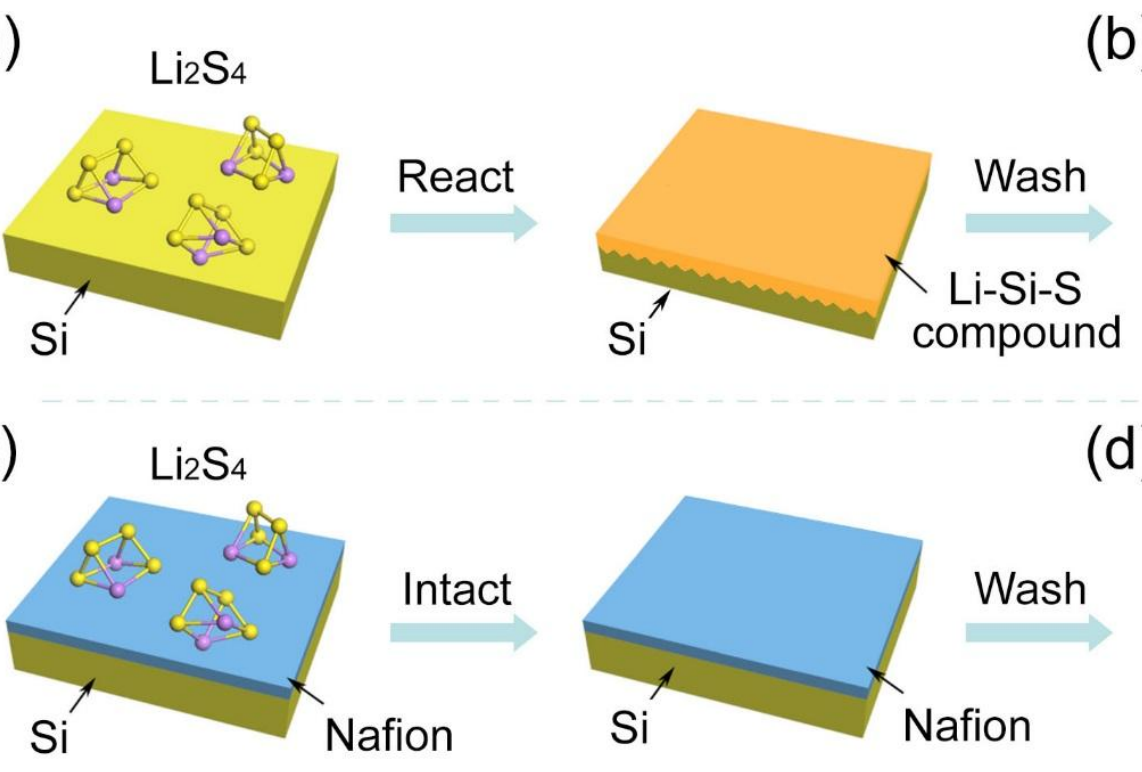

(b)

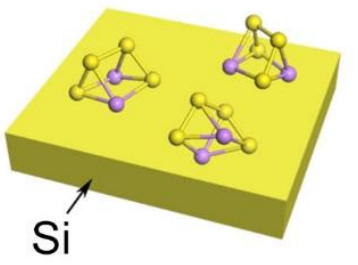

\section{React}

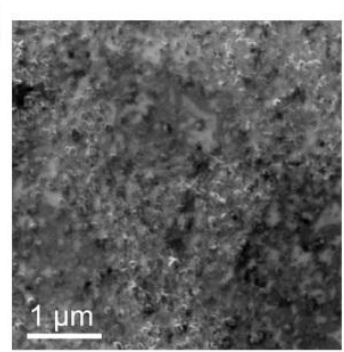

(d)
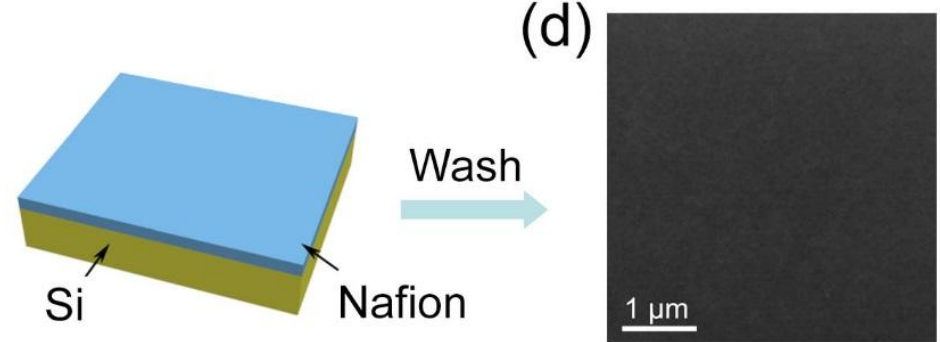
Figure 2
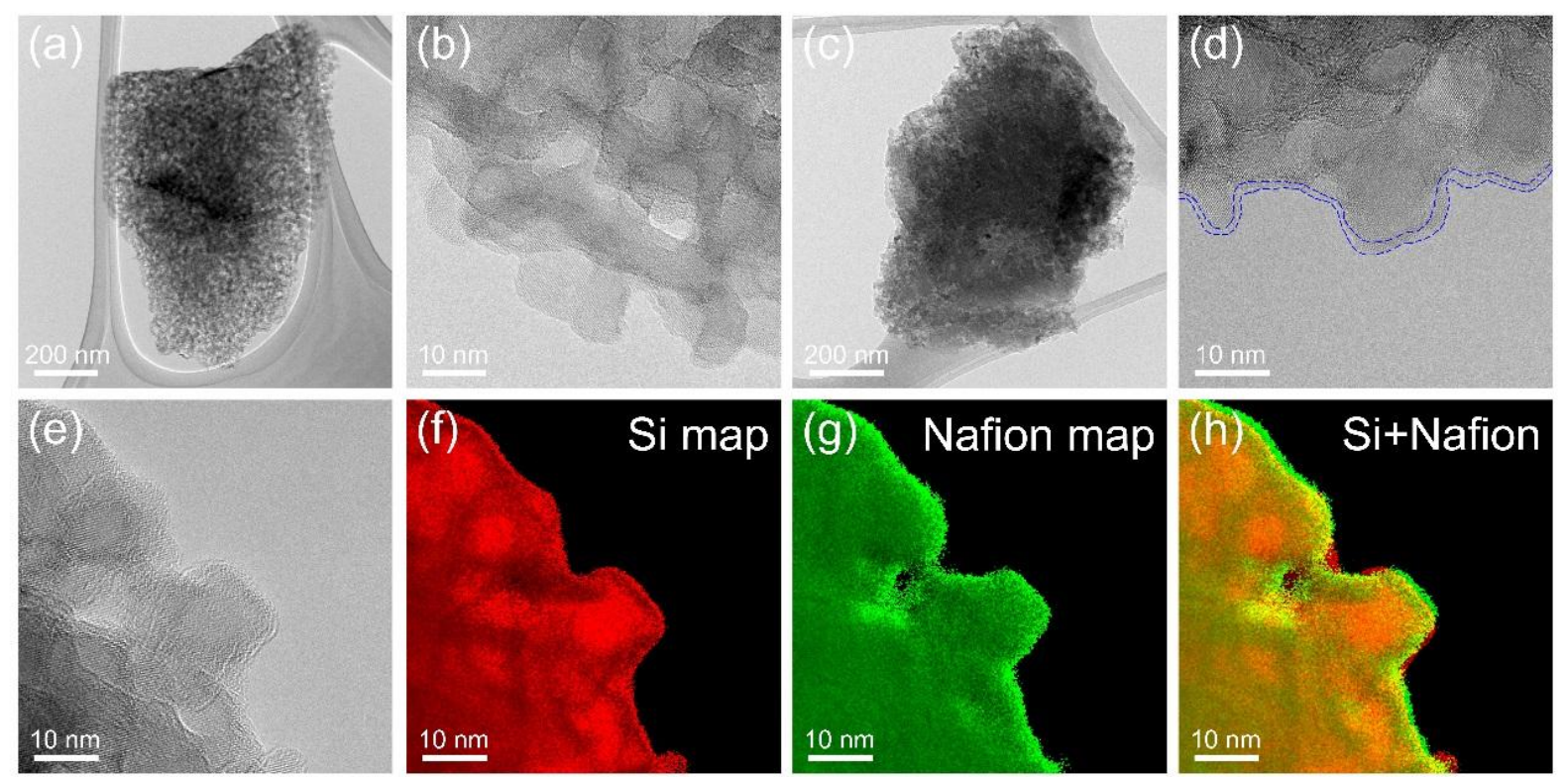
Figure 3

(a)

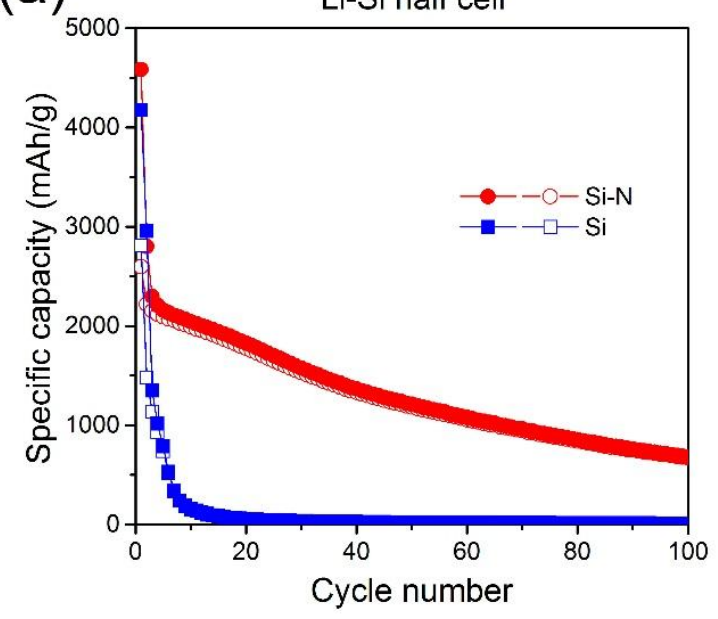

(b)

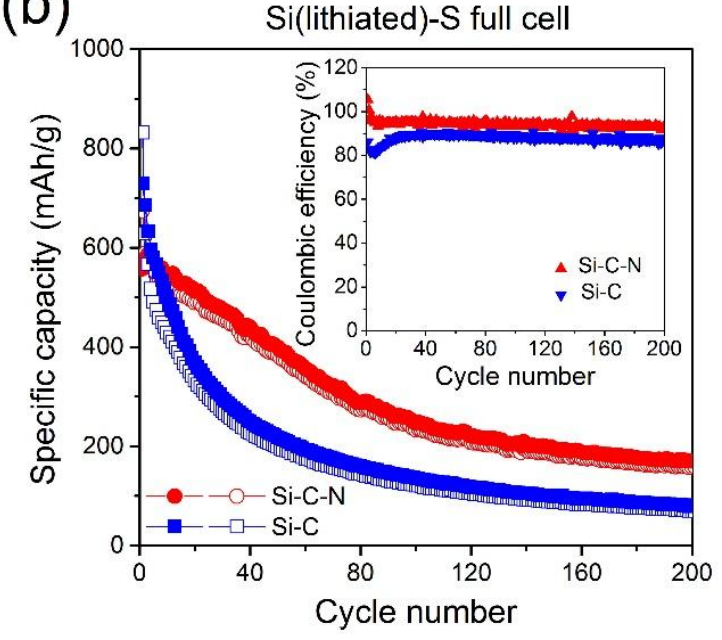




\section{Figure 4}
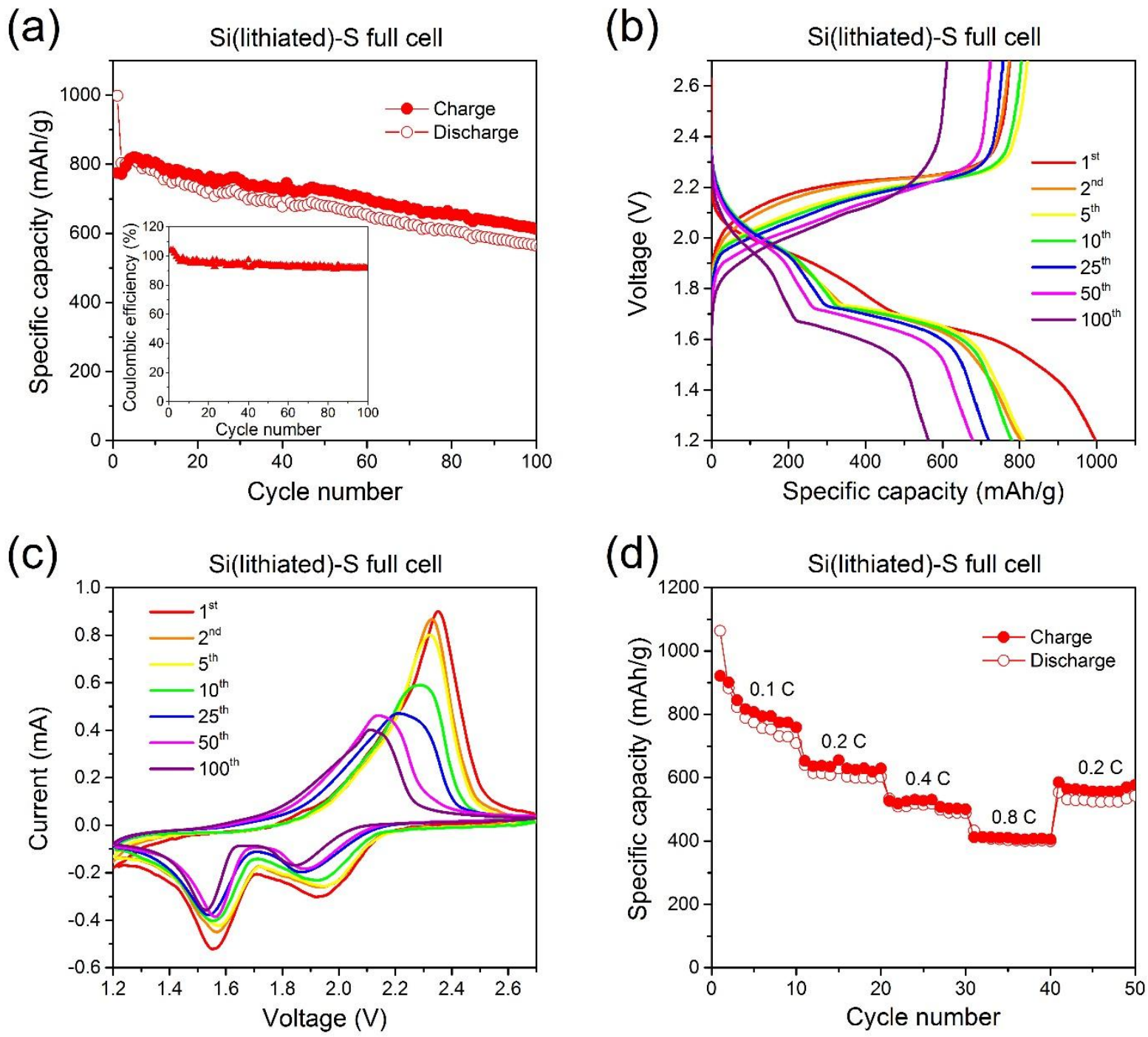


\section{Figure 5}
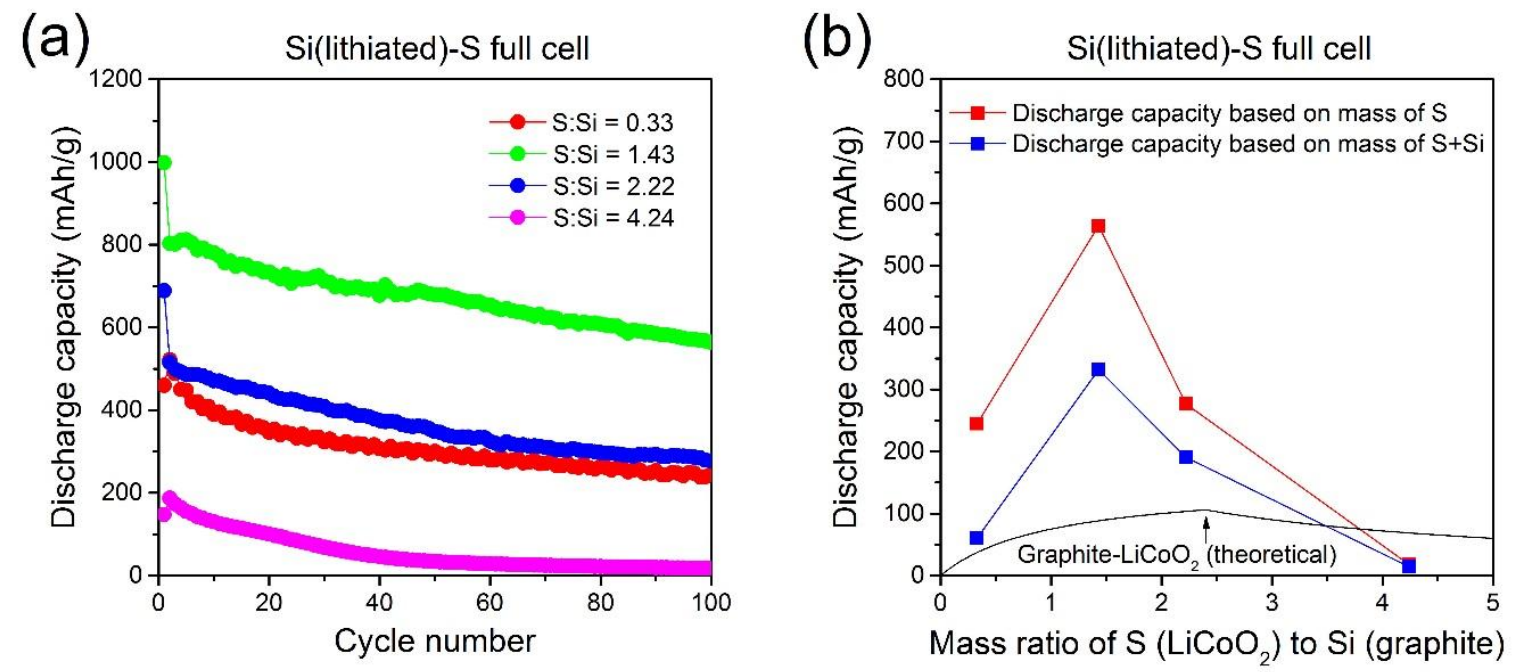


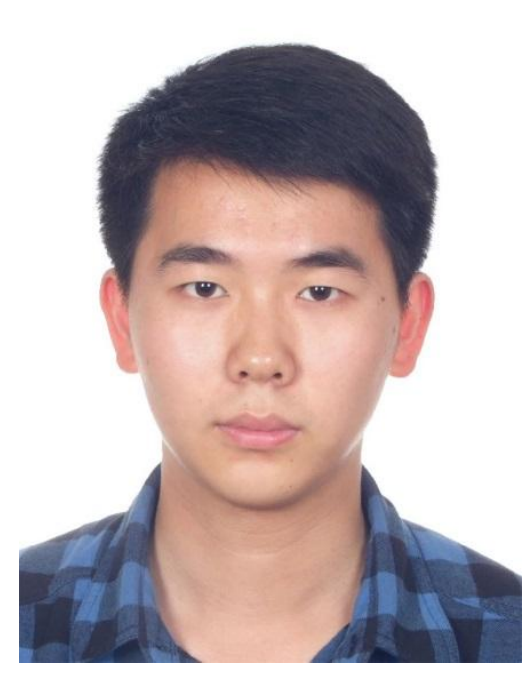

Chenfei Shen received his Bachelor's degree from Department of Materials Science at Nanjing University of Aeronautics and Astronautics in 2011 and Master's degree from University of California, Los Angeles in 2012. He is currently pursuing his $\mathrm{Ph}$.D. under the supervision of Prof. Chongwu Zhou at Mork Family Department of Chemical Engineering and Materials Science, University of Southern California. His research interests mainly focus on energy storage devices. 


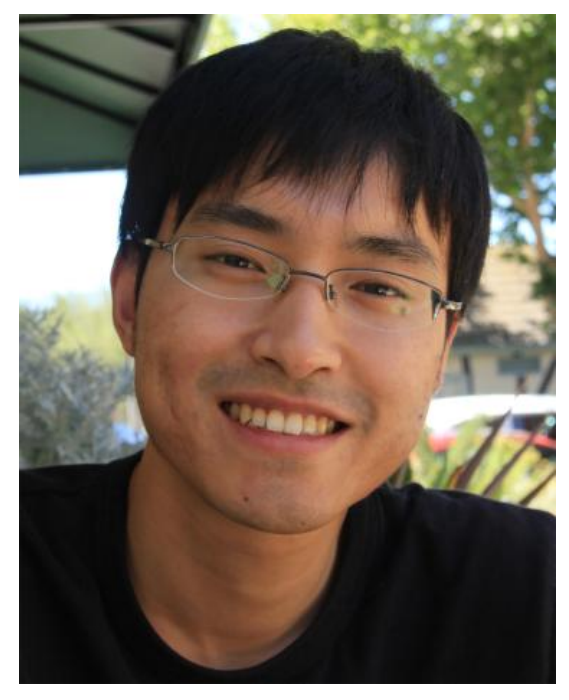

Dr. Mingyuan Ge is currently a postdoc research associate at National Synchrotron Light Source II at Brookhaven National Laboratory. He received his bachelor's degree in Materials Science from Zhejiang University and Ph.D. degree from University of Southern California. His research interests focus on the in-situ study of electrochemical properties of materials for energy storage and conversion applications. 


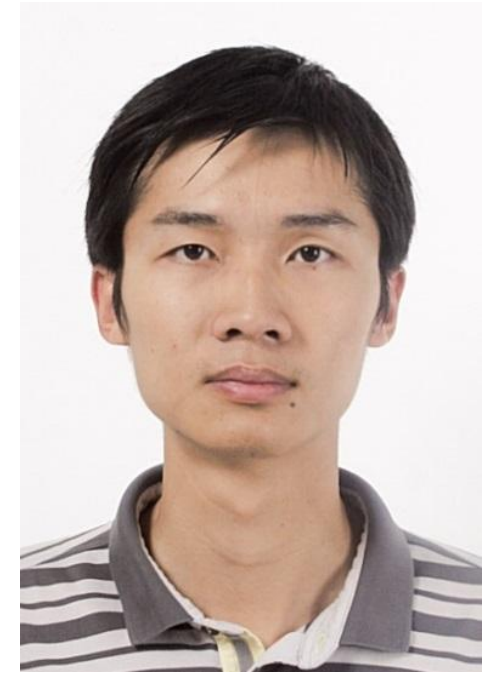

Anyi Zhang received his Bachelor's degree from the Department Chemical Engineering at Zhejiang University in 2011 and Master's degree from the Mork Family Department of Chemical Engineering and Materials Science at University of Southern California in 2013. He is currently pursuing his Ph.D under the supervision of Prof. Chongwu Zhou at Mark Family Department of Chemical Engineering and Materials Science, University of Southern California. His research interests mainly focus on lithium-sulfur Batteries. 


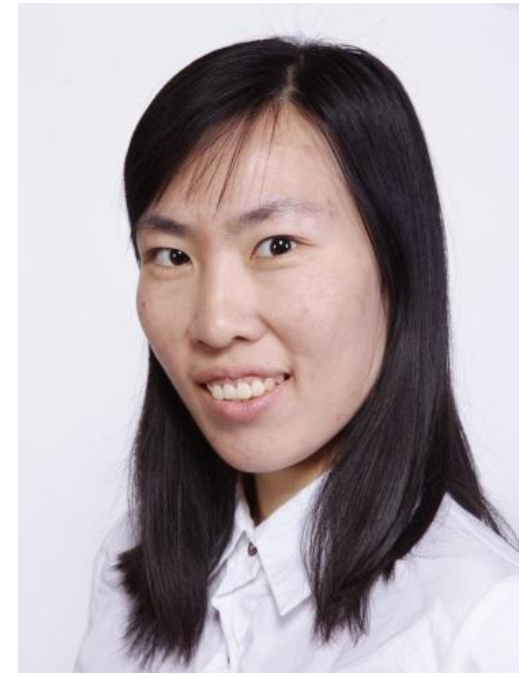

Xin Fang received her Bachelor's degree from University of Science and Technology of China in 2010. She is currently pursuing her Ph.D under the supervision of Prof. Chongwu Zhou in Mork Family Department of Chemical Engineering and Materials Science, University of Southern California. Her research mainly focuses on synthesis and modification of materials for energy storage and semiconductor devices. 


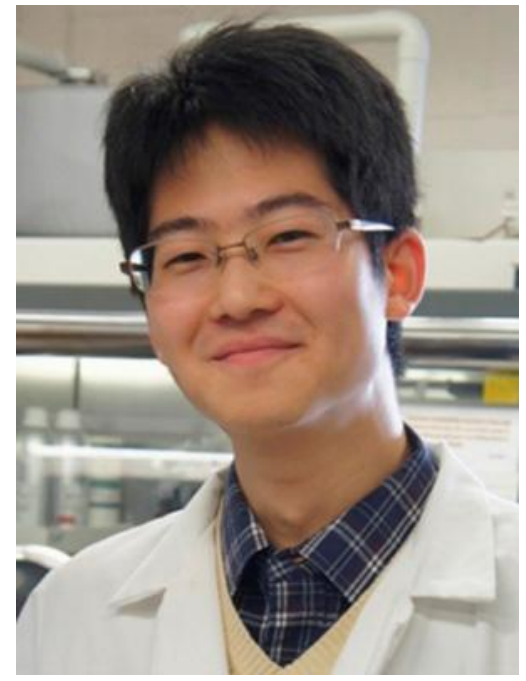

Yihang Liu is currently pursuing his Ph.D under the supervision of Prof. Chongwu Zhou in Ming Hsieh Department of Electrical Engineering at University of Southern California. He received a master degree in Chemical Engineering from University of Maryland, College Park and a bachelor degree in Opto-Electronic Engineering from Beijing Institute of Technology, China. His research interests are energy storage devices, including Li-ion and $\mathrm{Na}$-ion batteries. 


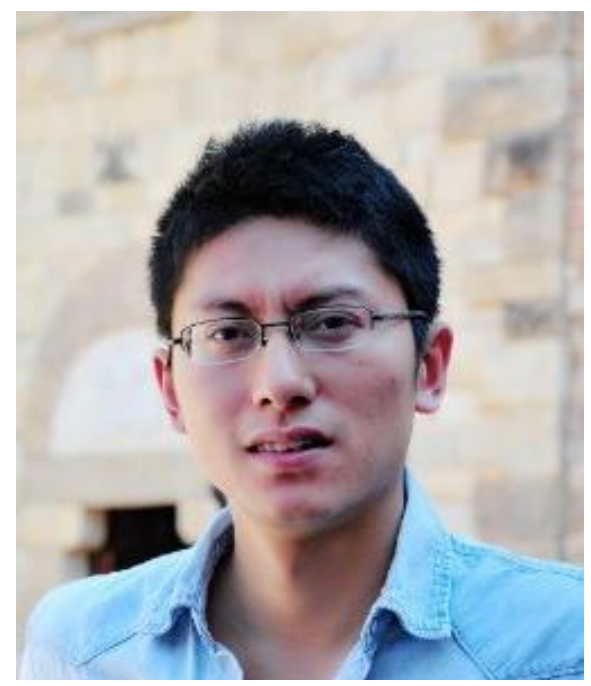

Dr. Jiepeng Rong received his Ph.D. from University of Southern California (USC), under the supervision of Prof. Chongwu Zhou. His research mainly focused on silicon-based anode materials and sulfur-based cathode materials for rechargeable lithium batteries. He's now working as senior battery cell engineer at Faraday Future Inc. 


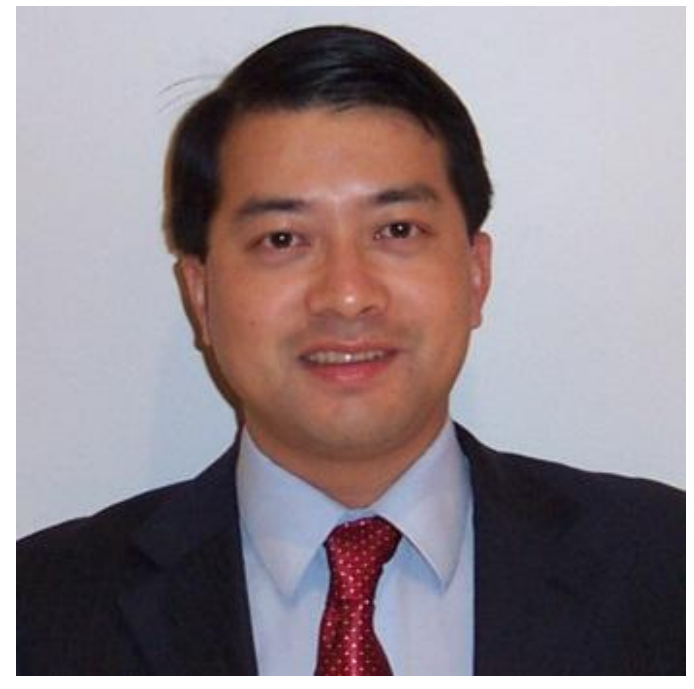

Dr. Chongwu Zhou is a full professor of Department of Electrical Engineering at University of Southern California (USC). He previously held positions of Jack Munushian Associate Professor (2006-2011) and Assistant Professor (2000-2006) at USC. He received Bachelor's Degree from the University of Science and Technology of China in 1993, received Ph.D. in Electrical Engineering from Yale University in 1999, and worked as a postdoc at Stanford University from 1998 to 2000. His research interest covers nanomaterials, nanoelectronics, energy nanotechnology, and bionanotechnology. $\mathrm{He}$ is an Associate Editor for Nanotechnology and IEEE Transactions on Nanotechnology, and serves as an Editorial Advisory Board member for ACS Nano. 